\title{
VIVER A PÓS-GRADUAÇÃO: LER E ESCREVER É PRECISO!
}

\author{
Eveline Boppré Besen Wolniewicz ${ }^{1}$ \\ Marimar da Silva² \\ Nilo Otani ${ }^{3}$
}

\begin{abstract}
RESUMO
$\mathrm{Na}$ pós-graduação, ler e escrever são habilidades linguísticas requisitadas com muita frequência aos estudantes. De cunho bibliográfico e reflexivo, o objetivo desse artigo é promover a reflexão sobre a importância da leitura crítica e da escrita acadêmica na formação de estudantes que escolheram viver a experiência da pós-graduação. Percebeu-se que é fundamental aprender a estudar, ler e escrever funcionalmente, como uma interação com o mundo mediada por sons e sinais gráficos. Por conseguinte, as informações disponíveis precisam ser transformadas em novas relações com o mundo e o desafio não se mostra de pequena proporção, uma vez que as pesquisas científicas sobre o tema apontam deficiências relacionadas à escolarização precária, dependência excessiva da bibliografia e esvanecimento do desejo de pensar dos estudantes.
\end{abstract}

Palavras-Chave: Leitura crítica. Escrita acadêmica. Estudante de pós-graduação.

\section{LIVING A GRADUATE PROGRAM: READING AND WRITING IS NEEDED!}

\begin{abstract}
In graduate programs, reading and writing are language skills and acts highly demanded from students. The purpose of this article is to promote reflection on the importance of critical reading and academic writing in the training of students who have chosen to live the graduate program experience. This study suggests that learning on how to study, to read and to write functionally, as an interaction with the world mediated by sounds and graphic signals is fundamental. Therefore, the information available needs to be resignified, creating new relations with the world but the challenge revealed not be simple, given that scientific research on the subject points to deficiencies related to precarious schooling, excessive dependence on bibliographic references, and the fading away of the student-thinking desire.
\end{abstract}

Keywords: Critical reading. Academic writing. Graduate student.

\footnotetext{
${ }^{1}$ Mestre em Educação Profissional e Tecnológica - Administradora - Universidade Federal de Santa Catarina - UFSC - e-mail eveline.boppre@ufsc.br

${ }^{2}$ Doutora em Inglês - Docente do Programa de Mestrado Profissional em Educação Profissional e Tecnológica em Rede Nacional (ProfEPT) no Instituto Federal de Santa Catarina - IFSC - e-mail marimar.silva@ifsc.edu.br

${ }^{3}$ Pós-doutor em Administração- Docente do Programa de Mestrado Profissional em Educação Profissional e Tecnológica em Rede Nacional (ProfEPT) no Instituto Federal de Santa Catarina - IFSC e-mail: nilo.otani@ifsc.edu.br
} 


\section{INTRODUÇÃO}

Estudantes ingressantes em cursos de pós-graduação frequentemente se deparam com duas questões pertinentes à construção de sua pesquisa científica: Como ler criticamente? Como escrever um texto dissertativo de qualidade? Por vezes, os estudantes apresentam receio de se exporem, de serem avaliados ou de receberem críticas em suas produções textuais. Grande parte deles chega à Universidade sem terem adquirido o adequado hábito da leitura e da escrita, muito embora as habilidades de ler e escrever demandadas pela academia sejam imprescindíveis para quem vive no mundo contemporâneo e vital para egressos de cursos de graduação que pretendem dar continuidade ao seu processo de aperfeiçoamento profissional.

A leitura pode ser compreendida como um processo interativo e dinâmico entre o leitor, o texto e o autor subsidiado pelas experiências prévias e pelo repertório teórico do leitor (MENDONÇA, OLIVEIRA, BURITI, GARGANTINI, 1997). Da mesma forma acontece com a escrita. Ao escrever academicamente, o estudante traz consigo suas experiências prévias e tudo o que ele já sabe sobre a escrita é relevante para a produção que the será exigida na universidade (JUCHUM, 2014).

$\mathrm{Na}$ formação de estudantes em um programa de pós-graduação, não se trata de ensinar gramática como uma coleção de regras que determinam o uso da norma culta da língua portuguesa, metodologia científica, ou ainda as normas técnicas que garantem a uniformidade de qualquer pesquisa científica (a exemplo da ABNT). Para se constituírem como formadoras, a leitura e a escrita precisam se concretizar como experiências (KRAMER, 1999).

Bianchetti (1996) e Meira (2007) apontam dificuldades de escrita de estudantes de pós-graduação e consideram que escrever não é fácil, pois exige leituras, esforço e persistência, além de expor o sujeito a avaliações nem sempre positivas. Nessa 
Criar Educação, Criciúma, v. 9, n², Edição Especial 2020.- PPGE - UNESC - ISSN 2317-2452

linha, Foucault (2004, p. 156) destaca que "escrever é mostrar-se, dar-se a ver, fazer aparecer o rosto próprio junto ao outro".

Não obstante os obstáculos enfrentados pelos estudantes, ler e escrever são tarefas indissociáveis da vida escolar e é evidente a responsabilidade da escola na formação de hábitos de leitura e de escrita dos seus estudantes. Quando ingressam no ensino universitário, ler criticamente e escrever textos são habilidades que, com muita frequência, são necessárias serem apresentadas por estudantes. Isto porque, por meio delas é possível desenvolver diversas competências profissionais relevantes para qualquer profissional de nível superior.

Entretanto, estudos como o de Duran (1981), Rubano (1987), Oliveira, Santos e Primi (2003), Oliveira e Santos (2008) e Oliveira (2011) evidenciam que estudantes universitários brasileiros não leem criticamente ou que apresentam repertório menos sofisticado ao que é esperado de estudantes de ensino superior.

A despeito da inegável relevância da leitura e da escrita no processo de aprendizagem de estudantes, poucos têm sido os trabalhos na última década que, no Brasil, têm interesse em lidar com a leitura de textos e a escrita acadêmica no ensino universitário como foco de investigação, conforme foi constatado na busca efetuada por assunto no portal de periódicos da Capes.

Este artigo pretende apontar elementos críticos relacionados à leitura crítica e à escrita acadêmica e alguns dos desafios postos aos estudantes que optam por viver a pós-graduação. De cunho qualitativo, a metodologia utilizada encontra-se ancorada em revisão de literatura sobre o tema.

Para dar conta do propósito, este artigo está organizado em 5 seções. Inicialmente a seção 1 , introdução, apresentou o tema, o objetivo geral, a justificativa e a metodologia da pesquisa. A seção 2 aprofunda a contextualização do problema. Na sequência, a seção 3 aborda a leitura crítica e a escrita acadêmica como condições necessárias à profissionalização. A seção 4 traz alguns dos desafios postos aos estudantes pós-graduandos e, por fim, a seção 5 delineia algumas considerações finais.

\section{CONTEXTUALIZAÇÃO DO PROBLEMA}


A expressiva relevância social da leitura e da escrita fez a escola assumir um papel central no processo de alfabetização dos estudantes. Esse processo, complexo ao aprendiz, requer uma mediação adequada para que o processo de ensinoaprendizagem, constituído por múltiplos componentes interativos entre professor e seus alunos, aconteça de maneira eficaz.

Neves, Souza, Schäffer, Guedes e Klüsener (2006) argumentam que ensinar a ler e a escrever é tarefa de todas as áreas do conhecimento, compromisso da escola e não exclusivamente do professor de português. Os autores salientam ainda a necessidade de que cada professor tenha um conhecimento profundo das características do ler e do escrever na sua área de atuação para que o diálogo entre elas seja profícuo. Nessa linha, Schäffer (2006) defende que professores das diferentes áreas reflitam sobre suas práticas e envidem esforços em direção à leitura e à escrita como tarefas escolares privilegiadas pela sociedade.

Não há dúvidas quanto à implicação social das habilidades de leitura e escrita para o exercício da cidadania, e as bases legais que sustentam a educação nacional, como a Lei de Diretrizes e Bases da Educação Nacional (LDBEN) e os Parâmetros Curriculares Nacionais (PCN), reportam-se ao que deve ser propiciado ao aluno desenvolver em relação à leitura e à escrita.

O texto da LDBEN (Brasil, 2013) ao tratar das etapas da Educação Básica, estabelece que desde o Ensino Fundamental seja priorizado na formação do aluno, o processo educativo com qualidade social, mediante o desenvolvimento da capacidade de aprender, tendo como meios básicos o pleno domínio da leitura, da escrita e do cálculo.

Em relação ao projeto político-pedagógico, a LDBEN (Brasil, 2013) prevê que as unidades escolares que ofertam ensino médio devem prever a valorização da leitura e da produção escrita em todos os campos de conhecimento. Contudo, apesar de todas essas proposições educacionais apresentadas, diversos trabalhos apontam que se lê muito pouco na escola, além de sérias deficiências relacionadas à 
escolarização precária, conforme indicam os resultados obtidos pelo Brasil no Programa Internacional de Avaliação de Estudantes (PISA) ${ }^{1}$.

O PISA avalia três domínios: leitura, matemática e ciências, sendo avaliado um domínio principal a cada edição. Em sua sétima edição, em 2018, o domínio principal foi leitura, sendo que os estudantes responderam a um maior número de itens no teste dessa área do conhecimento e uma gama mais ampla de textos foi utilizada na avaliação. Para melhor comparar internacionalmente o desempenho dos estudantes, o PISA tem como público-alvo estudantes entre 15 anos e 3 meses e 16 anos e 2 meses no momento da aplicação do teste e que completaram pelo menos seis anos de escolaridade formal.

Vale mencionar ainda que nessa última edição, o termo 'letramento em leitura' foi revisado, sendo acrescentada a avaliação de textos como parte integrante da definição: "o letramento em leitura refere-se a compreender, usar, avaliar, refletir sobre e envolver-se com textos, a fim de alcançar um objetivo, desenvolver seu conhecimento e seu potencial, e participar da sociedade" (INEP, 2019).

No caso específico da leitura, a média de proficiência dos jovens brasileiros foi de 413 pontos. Se comparado à média de 487 pontos dos países da Organização para Cooperação e Desenvolvimento Econômico (OCDE), o Brasil ocupa a faixa entre $55^{\circ}$ e $59^{\circ}$ no ranking. Cerca de $50 \%$ dos estudantes brasileiros não atingiram o mínimo de proficiência que todos os jovens devem adquirir até o final do ensino médio. Esse resultado representa um expressivo obstáculo na vida desses jovens, trazendo em seu bojo uma série de dificuldades para que esses estudantes avancem nos estudos, tenham melhores oportunidades de trabalho e participem plenamente da sociedade.

É sabido que uma das funções da universidade na sociedade do conhecimento consiste em auxiliar seus estudantes para que eles tenham senso crítico diante da

\footnotetext{
1 A prova que acontece a cada três anos é coordenada pela Organização para Cooperação e Desenvolvimento Econômico (OCDE) e foi aplicada no ano de 2018 em 79 países, entre 37 membros da OCDE e 42 países/economias parceiras, incluindo o Brasil. No total, participaram do teste 600 mil estudantes. No Brasil, envolveu 597 escolas públicas e privadas com 10.961 estudantes avaliados, distribuídos por todo o território nacional. O Pisa fornece um perfil básico de conhecimentos e habilidades dos estudantes e reúne informações relacionadas a variáveis demográficas, sociais, econômicas e educacionais de cada país (INEP, 2019).
} 
realidade social que os permeia, visando obter avanços científicos, tecnológicos e culturais. Todavia, Goecks (2011), ao revisar a literatura a respeito do comportamento de ler textos acadêmicos, encontrou diversos estudos que apresentam evidências que estudantes universitários brasileiros ingressam em cursos superiores sem compreender o que leem e que, muitas vezes, concluem suas graduações também sem compreender informações lidas, que não leem criticamente e que apresentam repertório de leitura de textos acadêmicos menos sofisticados em comparação ao que é desejável para estudantes de nível superior.

Duran (1981), citado por Oliveira, Santos e Primi (2003), afirma que esses repertórios de leitura pouco desenvolvidos de estudantes universitários principiantes, decorrem do fato de a leitura não ter sido desenvolvida apropriadamente ao longo do ensino fundamental e do ensino médio, associado a diversas desvantagens sociais.

Os resultados obtidos por Cabral e Tavares (2005), ao realizarem um estudo de diagnóstico em quatro universidades portuguesas a respeito da importância de ler, compreender e escrever para o sucesso acadêmico no ensino superior, apontam que essas competências desempenham uma função importante na aprendizagem dos estudantes e tendem a estar associadas ao seu desempenho acadêmico, embora as expectativas destes relativas ao desenvolvimento de tais competências não sejam atingidas.

No estudo desenvolvido por Mendonça et al. (1997) não foram identificadas diferenças expressivas nos objetivos de leitura por estudantes de graduação e pósgraduação, ou seja, o amadurecimento acadêmico não provocou modificações nos propósitos de leitura dos sujeitos.

Oliveira (1996), ao desenvolver um estudo para compreender os motivos de leitura dos estudantes universitários de cursos de Fonoaudiologia e Engenharia lerem textos, constatou a necessidade de programas de apoio à leitura para o universitário, de maneira a proporcionar-Ihe maior flexibilidade para atender às funções da leitura relacionadas no estudo de Greaney (1990), apresentadas e utilizadas como instrumento de pesquisa (escala de funções de leitura) por Oliveira (1996), a saber: 1) aprendizagem; 2) lazer; 3) fuga; 4) estímulo; 5) preencher o tempo; 6) alvos sociais definidos; 7) moralidade; 8) auto-respeito; 9) flexibilidade; 10) utilidade. 
Parece útil que medidas de intervenção sejam adotadas, uma vez que é possível perceber que estudantes de pós-graduação apresentam dificuldades em elaborar textos a partir de informações lidas em textos acadêmicos. Oliveira e Santos (2008) realizaram um estudo com estudantes universitários de um curso de administração de uma universidade privada do estado de São Paulo que frequentaram a disciplina 'leitura e produção de texto’ (LPT). Os resultados obtidos evidenciaram a importância de programas de incentivo e apoio à leitura, uma vez que os resultados apontam progresso na compreensão em leitura.

Ademais, no que se refere de modo específico a estudantes de pós-graduação, é importante ressaltar a importância do papel do orientador em indicar as leituras necessárias ao desenvolvimento do problema de pesquisa de interesse, evitando que o orientando se lance em um voo cego (ALVES-MAZZOTTI, 2002).

Enfim, é possível afirmar que tanto a habilidade de ler quanto a de escrever são desenvolvidas, dentre outros fatores, por meio da leitura de textos escritos por outros autores. Esse fato evidencia a relevância em ler textos acadêmicos de maneira apropriada, a qual pode ser avaliada por meio de textos elaborados a partir de informações lidas, uma vez que a qualidade da produção textual indica a qualidade da leitura realizada anteriormente.

\section{A LEITURA CRÍTICA E A ESCRITA ACADÊMICA COMO CONDIÇÕES NECESSÁRIAS À FORMAÇÃO DE PESQUISADORES}

Uma das atividades mais comuns solicitadas pelos professores a estudantes é a leitura de textos. Não raras vezes, os professores solicitam aos estudantes a realização de leituras de textos com "senso crítico". Mas o que significa esse comando, uma vez que convém dizer que ler um texto não é uma habilidade linguística simples - ela envolve complexos e variados graus de estímulos e exige sofisticadas percepções do leitor? Como maximizar a probabilidade de o estudante ler um texto com "senso crítico"?

Para Freire (1977), ler criticamente envolve o diálogo entre o leitor e o autor de um texto, acerca de temas desenvolvidos pelo autor. Essa "conversa" (nem sempre 
amistosa) requer que o leitor identifique o contexto histórico-social e ideológico do autor, que nem sempre é semelhante ao do leitor.

As ideias expressam relações que o homem estabelece com o contexto no qual se insere: "elas são a representação daquilo que o homem faz, da sua maneira de viver, da forma como se relaciona com outros homens, do mundo que o circunda e das suas próprias necessidades" (ANDERY, 2007, p. 12). Dentre as ideias que o homem produz, parte delas constitui o conhecimento referente ao mundo, que mesmo sendo parcial, ou expressando posições antagônicas, exprime condições materiais de um dado momento sócio-histórico (ANDERY, 2007).

Nesse sentido, é importante lembrar que os pós-graduandos indaguem em cada um dos textos lidos o que pode ser aproveitado, o que foi fecundo e que localizem as contribuições em relação ao momento histórico nos quais foram escritos e o avanço que representaram ou representam.

O professor deve ter clareza das razões pelas quais a leitura foi indicada em um determinado momento. Os objetivos da leitura e das atividades que se realizarão, utilizando as informações dos textos, fornecem os critérios para identificar, no texto, o que é importante retirar ou destacar. Botomé (1979), no artigo intitulado "Questões de estudo: uma condição para instalar discriminação de aspectos importantes de um texto" afirma que nem sempre o professor que indica ou fornece um texto, exigindo sua leitura, tem os mesmos objetivos do autor do texto.

Segundo Botomé (1979), um texto, para um professor, é um recurso utilizado para facilitar ao estudante:

a) acesso a algumas informações;

b) exame de alguns dados;

c) crítica a alguma opinião ou análise; e

d) o acesso a diversas atividades que podem diferir de nada a tudo o que o autor se propunha com o texto.

Levando em consideração os princípios da análise experimental do comportamento, a resposta de destacar aspectos importantes de um texto é uma resposta discriminada, ou seja, o estudante reage diferentemente diante de aspectos diferentes do texto. Uma das condições usualmente utilizadas por professores é a de 
fornecer ao estudante um roteiro de estudos. Ao investigar as condições necessárias para que os estudantes destaquem os aspectos importantes dos textos que recebem para estudo, Botomé (1979, p. 11-12) apresenta em linhas gerais três passos de como se organizaria um roteiro de estudos como condição para auxiliar um estudante a ler um texto adequadamente:

a) descrever quais os objetivos da leitura;

b) decidir qual a forma de destacar informações do texto - por exemplo, há professores que pedem para o estudante um fichamento do texto, outros pedem que o estudante destaque os aspectos relevantes com suas próprias palavras; e

c) analisar, decidir, planejar e organizar, utilizando as condições facilitadoras, que garantam que o estudante faça o que se espera - uma das condições usadas por professores é a de fornecer um roteiro de estudos contendo instruções, objetivos esperados e questões de estudo que o estudante deve responder utilizando as informações do texto.

Contribuindo para a temática, Hussein (1987) desenvolveu um estudo com o objetivo de analisar o conceito de leitura crítica apresentado na literatura científica. Dentre as três tendências identificadas pela autora, destaca-se a utilização das definições propostas pelos testes e instrumentos similares. Seguindo essa tendência, Cheves (1973), citada por Hussein (1987), considera como leitura crítica a habilidade para inferir através do texto, que é definida como habilidade de usar ideias e informações explicitamente apresentadas pelo texto e que fornecem base para conjecturar e levantar hipóteses. Vale mencionar que a autora encontrou definições variadas na literatura e concluiu que as habilidades contidas no conceito de leitura crítica poderiam ser melhor estudadas quanto ao seu nível de complexidade em leitores de diferentes níveis de escolaridade.

Por sua vez, Freire (1986, p. 52), ao relatar uma experiência com alfabetização de adultos, aborda a relevância da leitura crítica ao afirmar que:

O exercício desta atividade crítica, na análise da prática social, da realidade em processo de transformação possibilita aos alfabetizandos, de um lado, aprofundar o ato de conhecimento na pósalfabetização; de outro, assumir diante de sua quotidianidade uma posição mais curiosa. A posição de quem se indaga constantemente em torno da própria prática, em torno da razão de ser dos fatos em que se acha envolvido. 
Face ao destaque de Freire, é possível afirmar que a compreensão do texto por meio da leitura crítica implica perceber as relações (algumas sutis) entre o texto e o contexto e que dependem do repertório do estudante. Os professores contribuem ao indicarem textos que propiciem aos estudantes terem melhor consciência sobre o mundo e que sejam compreendidos como uma ferramenta de intermediação de processos, acontecimentos e experiências pessoais. Como a função do ensino é garantir aprendizagem, cabe ao professor aumentar a probabilidade de que, ao ler, o aluno consiga extrair do texto o que realmente importa para a sua aprendizagem.

Para Freire (1986), o ato de ler não se esgota na decodificação pura da palavra escrita ou da linguagem escrita. $O$ autor já havia afirmado desde a primeira edição do livro "A importância do ato de ler: em três artigos que se completam", publicada em 1982, que ler é um processo de interação com o meio e não envolve apenas identificar, decodificar e atribuir significado a sinais gráficos. Ou seja, ler e escrever extrapolam o reconhecimento e o desenho de sinais gráficos correspondentes a sons ou imagens de objetos.

É neste sentido que um texto deve auxiliar o leitor a aumentar a percepção dos fenômenos de interesse e a enxergar o mundo de uma forma diferente "com novas lentes" daquela que está acostumado, de forma a contribuir ao ampliar seu campo de visão.

Freire (1986, p. 11-12) afirma que "a leitura do mundo precede a leitura da palavra, daí que a posterior leitura desta não possa prescindir da continuidade da leitura daquele". O educador chama essa leitura que o aluno faz ao longo da escolarização de leitura da "palavramundo" (FREIRE, 1986, p. 12) e reforça a importância do ato de ler, como se estivesse fazendo a "arqueologia" da sua compreensão do complexo ato de ler ao longo de sua experiência de vida.

Com destaques semelhantes a Freire (1986), Kramer (1999) argumenta que para se constituírem como formadoras, a leitura e a escrita precisam se concretizar como experiências. O que faz da leitura uma experiência é o compartilhamento e, tanto quem lê, quanto quem propiciou a leitura ao escrever, aprendem, evoluem, são provocados. Nesse sentido, a autora afirma que não é o acúmulo de informação sobre clássicos, sobre gêneros ou sobre estilos, escolas ou correntes literárias que torna a 
leitura uma experiência, mas sim o modo de realização dessa leitura: se é capaz de ensejar uma reflexão para além do momento em que acontece; se é capaz de ajudar a compreender a história vivida e sistematizada ou contada nos livros.

No tocante à experiência, Fischer (2005, p. 07) também destaca que a leitura e a escrita acadêmica deveriam proporcionar o "exercício de pensar, estar simultaneamente dentro e fora de nós mesmos, de viver efetivamente experiências, no sentido de que as coisas que vivemos e produzimos nos abram ao que não somos nós mesmos (...)".

O estudante de pós-graduação empenhado na tarefa de relacionar os conceitos teóricos com fenômenos aos quais esses conceitos se referem certamente terá muitas surpresas até o final de sua leitura, sendo o aumento de visibilidade a respeito de fenômenos a principal decorrência da leitura crítica. Além disso, Rubano (1987) aponta outra importante decorrência do ler crítico - a transformação do sujeito que conhece e de sua atuação - constituindo-se em um instrumento de transformação social.

O ler crítico caracteriza-se como importante insumo para o desenvolvimento de competências profissionais relevantes para a sociedade para estudantes universitários, sendo que os dados levantados evidenciam a necessidade de novas pesquisas com enfoque no leitor adulto e a elaboração de estratégias curriculares de aprimoramento do leitor pós-graduando.

Em relação à escrita, o poeta chileno Pablo Neruda considera que escrever é tarefa fácil, basta começar com uma letra maiúscula, terminar com um ponto final e no meio colocar as ideias. Ironias à parte, Zinsser (2017) pondera que escrever não é um trabalho divertido nem fácil, mas sim solitário e árduo, sendo raras as frases que surgem prontas, ou seja, sem necessidade de serem reescritas.

No caso específico da escrita acadêmica, Ribeiro (1999) aborda de maneira resumida algumas fragilidades na elaboração de títulos e resumos nos trabalhos acadêmicos. O autor aponta quatro falhas principais:

a) palavras desnecessárias;

b) abuso da voz passiva; 
Criar Educação, Criciúma, v. 9, n²2, Edição Especial 2020.- PPGE - UNESC - ISSN 2317-2452

c) uso excessivo de palavras-chave no resumo, que já têm seu lugar numa relação a seguir; e

d) deficiência de conteúdo.

Além dessas falhas iniciais identificadas por Ribeiro (1999), Pereira (2013, p. 223) aponta inconsistências identificadas na revisão de literatura: "não raras vezes o que se verifica é o abuso de referências cruzadas que agenciam obras literárias, teorias científicas, formulações filosóficas e ensaios personalistas", cuja "seriedade" impressiona o leitor de frágil repertório.

Alves-Mazzotti (2002) descreve com humor, utilizando o recurso didático da caricatura, treze tipos de revisão de literatura frequentemente encontrados em relatórios acadêmicos e que devem ser evitados:

Quadro 1 - Tipos de revisão a serem evitados

\begin{tabular}{|c|c|}
\hline Tipos de revisão & Característica principal \\
\hline Summa & $\begin{array}{l}\text { Apresenta um resumo de toda a produção científica da cultura } \\
\text { ocidental sobre o tema }\end{array}$ \\
\hline Arqueológico & $\begin{array}{l}\text { Compactua da mesma preocupação exaustiva que caracteriza } \\
\text { o tipo anterior, porém distingue-se pela ênfase na visão } \\
\text { diacrônica }\end{array}$ \\
\hline Patchwork & $\begin{array}{l}\text { Copia e cola conceitos, pesquisas e afirmações de diversos } \\
\text { autores, sem um fio condutor }\end{array}$ \\
\hline Suspense & $\begin{array}{l}\text { Segue um roteiro, porém alguns pontos da trama permanecem } \\
\text { obscuros até o final }\end{array}$ \\
\hline Rococó & $\begin{array}{l}\text { Apresenta conceituações teóricas rebuscadas, meros } \\
\text { elementos decorativos que tentam atribuir elegância a dados } \\
\text { irrelevantes }\end{array}$ \\
\hline Cade & $\begin{array}{l}\text { Trata de maneira superficial mesmo os assuntos mais } \\
\text { complexos, não há aprofundamento do tema }\end{array}$ \\
\hline Coquetel teórico & $\begin{array}{l}\text { Para atender à indisciplina dos dados, apela para todos os } \\
\text { autores disponíveis na tentativa de esclarecer pontos obscuros }\end{array}$ \\
\hline Apêndice inútil & $\begin{array}{l}\text { Recusa-se a retomar o assunto em qualquer outra parte do } \\
\text { estudo após apresentar sua revisão de literatura }\end{array}$ \\
\hline Monástico & $\begin{array}{l}\text { Parte do princípio de que o estilo dos trabalhos acadêmicos } \\
\text { deve primar pela simplicidade }\end{array}$ \\
\hline Cronista social & $\begin{array}{l}\text { Encontra sempre uma oportunidade de citar autores da moda, } \\
\text { seja do Brasil ou do exterior }\end{array}$ \\
\hline $\begin{array}{l}\text { Colonizado versus } \\
\text { xenófobo }\end{array}$ & $\begin{array}{l}\text { Ou se baseia exclusivamente em autores estrangeiros ou não } \\
\text { admite citar literatura estrangeira }\end{array}$ \\
\hline Off the records & $\begin{array}{l}\text { Garante o anonimato às suas fontes ao negar o crédito a quem } \\
\text { o merece }\end{array}$ \\
\hline
\end{tabular}




\section{Ventríloquo}

Fala pela boca dos outros, abusa de paráfrases e de uma monótona sucessão de referências cruzadas

Adaptado de: Alves-Mazzotti (2002).

Botomé, Kubo e Cortegoso (2000) também apresentam importante contribuição ao compilarem os principais tipos de erros frequentes em dissertações de pós-graduandos e de professores universitários:

Quadro 2 - Erros de redação frequentes

\begin{tabular}{|c|}
\hline $\begin{array}{c}\text { Erros de redação usualmente encontrados em dissertações e } \\
\text { teses }\end{array}$ \\
\hline $\begin{array}{l}\text { 1. confusão entre "introdução" e "apresentação" em um texto } \\
\text { dissertativo }\end{array}$ \\
\hline $\begin{array}{l}\text { 2. uso de expressões que indicam afirmações extremas em } \\
\text { uma dissertação }\end{array}$ \\
\hline $\begin{array}{l}\text { 3. uso de expressões que indicam posição espacial sem } \\
\text { indicação de referentes }\end{array}$ \\
\hline $\begin{array}{l}\text { 4. uso de expressões que indicam localização temporal sem } \\
\text { referentes precisos }\end{array}$ \\
\hline 5. frases incompletas em um texto dissertativo \\
\hline $\begin{array}{l}\text { 6. uso de gírias e de expressões típicas da linguagem oral se } \\
\text { senso-comum em textos dissertativos }\end{array}$ \\
\hline $\begin{array}{l}\text { 7. ausência de elementos de coesão ou uso de elementos de } \\
\text { coesão inapropriados para ligação das sentenças em um texto } \\
\text { dissertativo }\end{array}$ \\
\hline erros gramaticais em um texto dissertativo \\
\hline $\begin{array}{l}\text { 9. uso de expressões com sinonímias inapropriadas e de } \\
\text { expressões redundantes }\end{array}$ \\
\hline uso inadequado de vírgulas em orações \\
\hline
\end{tabular}

Adaptado de: Botomé, Kubo e Cortegoso (2000).

Como se pode verificar, os autores enfatizam as principais "armadilhas" que afetam a qualidade do texto dissertativo e defendem características como clareza, precisão e fidedignidade na escrita.

Zinsser (2017), um dos mestres de escritores e jornalistas nos Estados Unidos em sua clássica obra "Como escrever bem" apresenta alguns conselhos para profissionais que pretendem expor suas ideias por meio de textos e que querem aprender a escrever com correção e coerência. Considera-se como uma das suas contribuições mais importantes o capítulo em que o autor reúne diversas orientações 
sobre o uso de verbos, advérbios, adjetivos, sinais de pontuação e de substantivos lições úteis para os que querem aprimorar a sua escrita.

Finalmente, em um programa de pós-graduação, é preciso aprender a estudar, ler e escrever funcionalmente, como uma interação com o mundo mediada por sons e sinais gráficos. E para ser funcional, têm que apresentar uma decorrência importante: as informações precisam ser transformadas em novas relações com o mundo e não apenas em "fetiches", que nas palavras de Eco (2006) prejudicam o discurso ao incorrerem em discussões polêmicas improdutivas e evasivas.

\section{VIVER A AVENTURA DA PÓS-GRADUAÇÃO}

Os programas de pós-graduação dificilmente conseguirão desempenhar sua função social se não forem capazes de ressignificarem seu papel na sociedade e no desenvolvimento da Ciência, da Tecnologia e do Ensino Superior. É algo inerente ao exercício profissional, portanto não deve ser negligenciado pelos programas de mestrado e doutorado.

Convém ressaltar que, no cerne da responsabilidade social dos programas de pós-graduação:

o processo de transformação de informações disponíveis em capacidade de atuar coerentemente com elas nas situações com que as pessoas se defrontam é de uma ordem mais complexa do que ler ou ouvir e anotar, repetir, adotar, seguir regras ou modelos. As situações que ocorrem no meio em que a pessoa vive (e que constituem suas circunstâncias de vida) podem ser vistas de forma diferente com os "óculos do conhecimento", mas não se confundem com as verbalizações, textos ou imagens que apresentam o conhecimento existente (BOTOMÉ; KUBO, 2002, p. 89).

A sociedade precisa de profissionais com perfil investigativo para atuar não apenas nas universidades, mas também nas empresas. Pessoas revestidas de seriedade, compromisso social, dedicação, capazes de transformar o conhecimento científico em atuações profissionais significativas para a sociedade, seja nas empresas, seja nas organizações que se preocupam com o acesso ao conhecimento e sua difusão ou ampla utilização na sociedade: o que pressupõe ler e escrever adequadamente (BOTOME; KUBO, 2002). 
Luna (2000) afirma que o papel do pesquisador passa a ser o de um intérprete da realidade pesquisada e espera-se que ele seja capaz de demonstrar segundo critérios convincentes que o conhecimento que ele produz é fidedigno e relevante teórica e socialmente.

O futuro dos jovens pesquisadores deveria ser de descoberta e ousadia em relação ao desconhecido, embora muitas vezes seja fortemente influenciado pelo desejo imediatista de aumentar os rendimentos com o título acadêmico por meio da progressão na carreira, principalmente em relação aos servidores públicos concursados.

Ribeiro (1999) afirma que quando se fazem seminários ou grupos de discussão de textos, quando se estudam os textos de referência, quando se conhece bem a bibliografia, isso tanto pode ajudar a desencadear a reflexão, quanto pode atá-la a modelos já constituídos. $O$ autor constatou que em muitos trabalhos ditos de pesquisa, primeiro se procura uma bibliografia de referência, a qual depois é aplicada mecanicamente a um objeto de estudo e esclarece que é preciso que a bibliografia sirva de ajuda para produzir conhecimento inovador sobre o fenômeno escolhido e não de "muletas" (RIBEIRO, 1999).

Além disso, examinar a abrangência e em que contexto ocorre o fenômeno, além de aproveitar as múltiplas contribuições das áreas de conhecimento é fundamental. Convém sempre perguntar: quais descobertas foram feitas a partir da leitura? Que pistas o texto oferece que contribuem para compreensão do problema de pesquisa?

Para Freire (1977), o estudo de um tema específico requer que o estudante se ponha, tanto quanto possível, cônscio da bibliografia que se refere ao tema ou ao objeto de sua inquietude. No meio acadêmico, as atividades de leitura e escrita não deveriam manter-se reféns de encontrar ou produzir verdades absolutas, repetir clichês geralmente repletos de associações livres que com frequência adulteram ou anulam aquilo que é relevante no que está originalmente escrito ou foi dito por alguém. Pereira (2013, p. 226) alerta que "um texto não tem que ser um exercício de ventriloquismo ou mimetismo acadêmico, mas de outro modo, um exercício analítico e argumentativo que permita que o autor fale por si". Fischer (2005, p. 11-13), por sua 


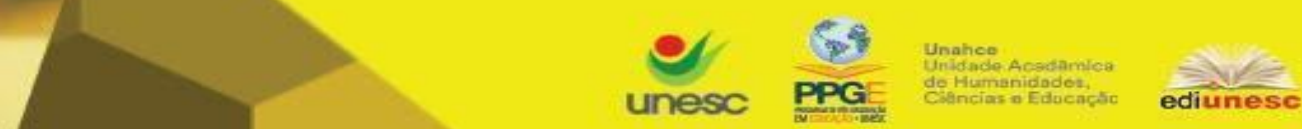

Criar Educação, Criciúma, v. 9, n², Edição Especial 2020.- PPGE - UNESC - ISSN 2317-2452

vez, afirma que "insistimos em tratar referenciais teóricos como se fossem verdadeiras ferramentas de transparência e da mesmidade" e propõe a seguinte reflexão: "como poderemos produzir um texto que também faça a diferença para nós e para os que nos lerão?"

A resposta não é fácil. Talvez esteja na direção do que Postman e Weingartner afirmaram há aproximadamente cinquenta anos atrás no livro "Contestação - Nova fórmula de ensino":

devemos recorrer a homens cujos livros raramente seriam usados - nem mesmo lembrados - nos cursos de educação e que não figuram, nas bibliotecas, na seção de "Educação" (...) O que está fazendo falta é uma espécie de terapia de choque, com um estímulo fornecido por outras fontes mais vivas (1974, p. 16-17).

Warde (1990), ao efetuar revisão de literatura acerca do papel da pesquisa na pós-graduação em educação, constatou, dentre outros aspectos, que sobressaem as críticas de "pobreza teórica" e "inconsistência metodológica" sobre a produção nessa área de conhecimento, que os temas das pesquisas no contexto da pós-graduação apresentam avanços temáticos; contudo, tendem à escolha de temas irrelevantes, socialmente pouco significativos, de caráter fragmentário e descontínuo.

Ribeiro (1999) refere-se ao "esvaziamento do desejo de pensar" na maneira como os jovens pesquisadores abordam seus temas e sugere que os temas de estudo na área de ciências humanas, que geralmente têm a ver com o desejo de cada um, sejam explorados com maior liberdade e ousadia. Questiona se talvez não falte aos pesquisadores uma maneira mais livre de perguntar em relação ao que é desconhecido, de lidar com o que de melhor foi produzido no campo da cultura, com o patrimônio artístico cultural e, com isso, contribuir para aumentar a visibilidade sobre os fenômenos. Lançando mão da metáfora como figura de linguagem, aponta a 'terra firme como pior inimigo do conhecimento'.

Já Freitas (2002) ressalta que a tese deve preencher uma função social, a de avançar no conhecimento de certo assunto e se justifica pelo potencial de mudança que propiciará. Neste sentido, o eixo norteador deve ser sempre a sociedade, o insumo do pesquisador deve levar em conta as necessidades sociais, apesar dessas quase sempre serem desconhecidas. Num processo de retroalimentação constante 


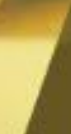

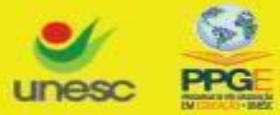 \\ Unahoe \\ unesc \\ PPG \\ ediunese}

Criar Educação, Criciúma, v. 9, n², Edição Especial 2020.- PPGE - UNESC - ISSN 2317-2452

proporcionado pela pesquisa séria e responsável, ocorre produção de conhecimento novo, relevante, acessível, além do desenvolvimento de comportamentos significativos e de alto valor.

\section{CONSIDERAÇÕES FINAIS}

A construção de uma dissertação ou de uma tese exige leitura crítica e constante produção textual: "criar algo significa ter humildade e disponibilidade psicológica para tentar, expor-se, errar, recomeçar, modificar, experimentar, observar" (FREITAS, 2002, p. 93). Além disso, a dissertação e a tese são componentes indissociáveis da formação de um pesquisador, e serão elementos multiplicadores onde quer que ele esteja. Desenvolvê-las com qualidade e aprender a superar comportamentos típicos de repertórios de senso-comum, torna-se imprescindível a estudantes de um programa de pós-graduação.

Desprovido da capacidade de ler criticamente os conteúdos ministrados, o estudante fica vulnerável àqueles ou àquilo que elaborarem por ele e essa situação não contribui para a formação de um profissional crítico e reflexivo capaz de atuar de maneira transformadora no mundo.

Além disso, os dados obtidos evidenciam a necessidade de mais pesquisas sobre a leitura crítica e a escrita acadêmica no âmbito do ensino superior e, consequentemente, de novas estratégias curriculares para aprimoramento da formação do estudante pós-graduando.

Ressalta-se ainda a importância de os programas de pós-graduação, especialmente os da área de ensino, manterem-se fortemente engajados na promoção do avanço do conhecimento, assim como de sua divulgação o (tornar acessível a quem deles necessita) e das possibilidades de seu uso para fins de atuação em situações sociais, assim como promover o avanço do conhecimento. Há de se considerar que a área de ensino é essencialmente uma área de pesquisa traslacional, a qual busca construir relações entre conhecimentos acadêmicos produzidos em educação e ensino para sua aplicação em produtos e processos educativos na sociedade (MEC, 2016). 
investigativos III: riscos e possibilidades de pesquisar nas fronteiras. Rio de Janeiro: DP\&A, p. 117-140, 2005. Disponível em:

https://pedagogiascontemporaneas.files.wordpress.com/2017/08/fischer-rosa-mariabueno-escrita-academica-arte-de-assinar-o-que-se-le.pdf. Acesso em: 9 nov. 2018.

FOUCAULT, Michel. Ditos \& Escritos V: ética, sexualidade, política. Rio de Janeiro: Forense Universitária, 2004.

FREIRE, Paulo. Ação cultural para a liberdade e outros escritos. 2. ed. Rio de Janeiro: Paz e Terra, 1977.

FREIRE, Paulo. A importância do ato de ler: em três artigos que se completam. 15 ed. São Paulo: Cortez, 1986.

FREITAS, Maria Ester de. Viver a tese é preciso! Reflexões sobre as aventuras e desventuras da vida acadêmica. Revista de Administração de Empresas (RAE), São Paulo, v. 42, n. 1, p. 88-93, 2002. Trimestral. Disponível em: http://www.scielo.br/pdf/rae/v42n1/v42n1a09.pdf. Acesso em: 2 nov. 2018.

GOECKS, Cláudia Alice. Comportamentos Constituintes da Classe Geral de "Ler textos acadêmicos". 2011. 129 f. Dissertação (Mestrado) - Curso de Programa de Pós-graduação em Psicologia, Psicologia, Universidade Federal de Santa Catarina, Florianópolis, 2011. Disponível em: https://repositorio.ufsc.br/handle/123456789/95870. Acesso em: 3 nov. 2018

HUSSEIN, Carmem Lúcia. Leitura Crítica: revisão do conceito. Rio de Janeiro, Arquivo Brasileiro de Psicologia, v. 39, n. 3, p. 108-115, 1987.

INEP. Instituto Nacional de Estudos e Pesquisas Educacionais Anísio Teixeira. Relatório Brasil no PISA 2018: versão preliminar. Disponível em: http://portal.inep.gov.br/web/guest/acoes-internacionais/pisa/resultados. Acesso em: 2 jun. 2020.

JUCHUM, Maristela. A escrita na universidade: uma reflexão com base no que os alunos dizem em seus textos. Revista Horizontes de linguística aplicada, v. 13, n. 1, p. 107-129, 2014. Disponível em:

https://periodicos.unb.br/index.php/horizontesla/article/view/1339.

Acesso em: 2 jun. 2020.

KRAMER, Sônia. Leitura e escrita como experiência: notas sobre seu papel na formação. In: ZACCUR, Edwiges (org). A magia da linguagem. Rio de Janeiro: DP\&A, 1999, p. 101-121.

LUNA, Sérgio Vasconcelos de. Planejamento de Pesquisa: Uma Introdução. São Paulo: EDUC, 2000. 
MEC. Ministério da Educação. Documento de área: ensino. 2016. Disponível em: http://capes.gov.br/images/documentos/Documentos_de_area_2017/DOCUMENTO_ AREA_ENSINO_24_MAIO.pdf. Acesso em: 5 nov. 2018.

MEIRA, Ana Cláudia Santos. A escrita científica no divã: entre as possibilidades e as dificuldades para com o escrever. Porto Alegre: EdiPucRS, 2007.

MENDONÇA, Gracieli G. Lopes de; OLIVEIRA, Maria Helena Mourão Alves; BURITI, Marcelo de Almeida; GARGANTINI, Marisa Bueno Mendes. As funções da leitura para graduandos e pós-graduandos. Estudos de Psicologia, v. 14, n. 1, p. 37-46, 1997. Disponível em: http://www.scielo.br/pdf/estpsi/v14n1/04.pdf. Acesso em: 30 out. 2018.

NEVES, lara Conceição Bitencourt; SOUZA, Jusamara Vieira; SCHÄFFER, Neiva Otero; GUEDES, Paulo Coimbra; KLÜSENER, Renita. Ler e escrever:

Compromisso de todas as áreas. 7. ed. Porto Alegre: Editora da UFRGS, 2006.

OLIVEIRA, Maria Helena Mourão Alves de. Funções da leitura para estudantes de graduação. Psicologia Escolar e Educacional, Campinas, v. 1, n. 1, p. 61-68, 1996. Disponível em: http://www.scielo.br/pdf/pee/v1n1/v1n1a09.pdf. Acesso em: 8 nov. 2018.

OLIVEIRA, Katya Luciane de; SANTOS, Acácia Aparecida Angeli dos; PRIMI, Ricardo. Estudo das relações entre compreensão em leitura e desempenho acadêmico na universidade. Interação em Psicologia, Curitiba, v. 7, n. 1, p. 19-25, 2003. Disponível em: http://revistas.ufpr.br/psicologia/article/view/3203/2565. Acesso em: 4 nov. 2018.

OLIVEIRA, Katya Luciane de; SANTOS, Acácia Aparecida Angeli dos. Estudo de intervenção para a compreensão em leitura na Universidade. Interação em Psicologia, v. 12, n. 2, p. 169-177, 2008. Disponível em: https://revistas.ufpr.br/psicologia/article/download/9575/10246. Acesso em: 18 nov. 2018.

OLIVEIRA, Katya Luciane de. Considerações acerca da compreensão em leitura no ensino superior. Revista Psicologia ciência e profissão, v. 31, n. 4, p. 213-224, 2011. Disponível em: http://www.scielo.br/scielo.php?script=sci_arttext\&pid=S141498932011000400003. Acesso em: 18 nov. 2018.

PEREIRA, Marcos Villela. A escrita acadêmica: do excessivo ao razoável. Revista Brasileira de Educação, v. 18, n. 52, p. 213-224, 2013. Disponível em: http://www.scielo.br/pdf/rbedu/v18n52/13.pdf. Acesso em: 10 nov. 2018.

POSTMAN, Neil; WEINGARTNER, Charles. Contestação: nova fórmula de ensino. Rio de Janeiro: Ed. Expressão e Cultura, 1974. 


\section{CRIAR EDUCAÇÃO}

Revista do Programa de Pós-Graduação em Educação - UNESC

Criar Educação, Criciúma, v. 9, n², Edição Especial 2020.- PPGE - UNESC - ISSN 2317-2452

RIBEIRO, Renato Janine. Não há pior inimigo do conhecimento que a terra firma.

Revista Tempo Social - Revista Sociologia da USP, São Paulo, v. 11, n. 1, p. 189195, 1999. Disponível em: http://www.revistas.usp.br/ts/article/view/12300/14077.

Acesso em: 6 nov. 2018.

RUBANO, Denize Rosana. A leitura na universidade: análise do comportamento de ler como um referencial para a investigação de variáveis. 1987. $195 \mathrm{f}$.

Dissertação (Mestrado) - Curso de Programa de Pós-graduação em Psicologia

Experimental, Instituto de Psicologia, Universidade de São Paulo, São Paulo, 1987.

SCHÄFFER, Neiva Otero. Ler a paisagem, o mapa, o livro: Escrever nas linguagens da geografia. In: NEVES, lara Conceição Bitencourt et al. (org.). Ler e escrever: Compromisso de todas as áreas. 7. ed. Porto Alegre: Editora UFRGS, p. 86-103, 2006.

WARDE, Mirian. O papel da pesquisa na pós-graduação. Caderno de Pesquisa, São Paulo, v. 73, p. 67-75, 1990. Disponível em:

http://publicacoes.fcc.org.br/ojs/index.php/cp/article/view/1098/1103. Acesso em: 1 nov. 2018.

ZINSSER, William. Como escrever bem: o clássico manual americano de escrita jornalística e de não ficção. São Paulo: Três Estrelas, 2017.

Recebido março de 2019

Aprovado junho de 2020 